\title{
Enhanced Attenuation of Meningeal Inflammation and Brain Edema by Concomitant Administration of Anti-CD18 Monoclonal Antibodies and Dexamethasone in Experimental Haemophilus Meningitis
}

\author{
Xavier Sáez-Llorens, Hamid S. Jafari, Carlos Severien, Francisco Parras, Kurt D. Olsen, \\ Eric J. Hansen, Irwin I. Singer, ${ }^{*}$ and George H. McCracken, Jr. \\ Departments of Pediatrics and Microbiology, University of Texas Southwestern Medical Center, Dallas, Texas 75235-9063; and \\ *Department of Biochemical and Molecular Pathology, Merck Sharp \& Dohme Research Laboratories, Rahway, New Jersey 07065
}

\begin{abstract}
Antiinflammatory therapy has been shown to reduce the adverse pathophysiological consequences that occur in bacterial meningitis and to improve outcome from disease. In the present study, modulation of two principal steps of the meningeal inflammatory cascade was accomplished by concomitant administration of dexamethasone to diminish overproduction of cytokines in response to a bacterial stimulus and of a monoclonal antibody directed against adhesion-promoting receptors on leukocytes to inhibit recruitment of white blood cells into the subarachnoid space. Dexamethasone and antibody therapy produced a marked attenuation of all indices of meningeal inflammation and reduction of brain water accumulation after $\boldsymbol{H}$. influenzae-induced meningitis in rabbits compared with results of each agent given alone and of untreated animals. In addition, the enhanced host's meningeal inflammatory reaction that follows antibiotic-induced bacterial lysis was profoundly ameliorated when dual therapy was administered without affecting clearance rates of bacteria from cerebrospinal fluid and vascular compartments. The combination of both therapeutic approaches may offer a promising mode of treatment to improve further the outcome from bacterial meningitis. (J. Clin. Invest. 1991.88:2003-2011.) Key words: anti-CD18 antibodies $\bullet$ dexamethasone • experimental meningitis
\end{abstract}

\section{Introduction}

Antiinflammatory therapy of animals and humans with bacterial meningitis has been shown to decrease meningeal inflammation, blood-brain barrier permeability, intracranial hypertension, brain edema, tissue damage, long-term neurological sequelae, and mortality rates associated with this disease $(1,2)$. Likewise, the transient enhancement of the host's inflammatory response that commonly follows initiation of antibiotic treatment has been significantly attenuated when agents have been used that selectively interfere with production of inflammatory mediators (e.g., dexamethasone, cyclooxygenase inhibitors) or with influx of leukocytes into the subarachnoid space (e.g., pentoxifylline, anti-CD18 receptor antibodies) (3-6).

Address correspondence to George H. McCracken, Jr., M.D., Dept. of Pediatrics, UT Southwestern Medical Center, 5323 Harry Hines Blvd., Dallas, TX 75235-9063.

Received for publication 16 January 1991 and in revised form 29 July 1991.

J. Clin. Invest.

(c) The American Society for Clinical Investigation, Inc.

$0021-9738 / 91 / 12 / 2003 / 09 \$ 2.00$

Volume 88, December 1991, 2003-2011
Elevated concentrations of proinflammatory substances such as TNF and IL-1 trigger initiation of the inflammatory process and provoke profound pathophysiological changes that result in alteration of cerebrospinal fluid (CSF) ${ }^{1}$ hydrodynamics and in activation of the metabolic and coagulation pathways (7-9). Dexamethasone has been shown to inhibit production of these cytokines at transcriptional and translational levels, especially when given before liberation of active bacterial components into the subarachnoid space $(10,11)$.

Influx of leukocytes into CSF can further amplify these pathophysiologic events because their accumulation contributes to a sluggish CSF circulation and decreased resorption, and because of liberation of cytotoxic products on degranulation (12). Before entering the subarachnoid space leukocytes must adhere to brain endothelial cells presumably through a family of adhesion-promoting receptors and ligands located on leukocyte cell membranes and endothelium that have been previously activated by exposure to cytokines $(13,14)$. Treatment of experimental lapine meningitis induced by intracisternal inoculation of living bacteria (e.g., S. pneumoniae, $H$. influenzae, $N$. meningitidis), their cell wall components (e.g., teichoic acid, lipopolysaccharide), or by human cytokines with monoclonal antibodies (MAbs) directed against the CD11/CD18 leukocyte adhesion receptors was shown to decrease transendothelial passage of polymorphonuclear cells into CSF and to reduce significantly indices of meningeal inflammation $(6,15)$. The use of anti-CD18 MAbs has also been shown to inhibit polymorphonuclear leukocyte accumulation and plasma leakage in rabbits with experimentally-induced inflammatory skin lesions (16) and to reduce multiple organ injury and death caused by increased leukocyte adhesiveness in an experimental model of generalized ischemia-reperfusion injury (17).

The aim of this study was to assess whether the combination of dexamethasone (DXM) and anti-CD11/CD18 antibodies would be more effective than either agent alone in preventing or attenuating the pathophysiologic events that occur in experimental meningitis induced by $H$. influenzae type b or its purified lipooligosaccharide (LOS).

\section{Methods}

\section{Preparation of Hib endotoxin}

Hib endotoxin (LOS) was purified from cells of Hib strain DL42 by using the hot phenol-water method of Westphal and Jann (18), as modified by Johnson and Perry (19). The purity of this LOS preparation was confirmed by SDS-PAGE, followed by silver staining (20) and

1. Abbreviations used in this paper: CSF, cerebrospinal fluid; DXM, dexamethasone; LOS, lipooligosaccharide. 
Western blot analysis using hyperimmune rat serum to Hib DL42 (21) $20 \mathrm{ng}$ of the endotoxin, which is contained in $\sim 2 \times 10^{6}$ bacterial cells, was chosen as the inoculum to induce meningitis because this amount has consistently induced meningeal inflammation in this rabbit model (22) and because CSF samples from patients with Hib meningitis contain from $10^{4}$ to $10^{7} \mathrm{CFU} / \mathrm{ml}$.

\section{Bacterial strain}

Hib strain DL42 is a non- $\beta$-lactamase-producing strain isolated from the CSF of a child with meningitis. This strain is fully virulent in the infant rat model for Hib invasive disease and belongs to LOS antigenic group 2, which is the predominant LOS antigenic type among invasive Hib isolates (23). The minimum inhibitory concentration of ceftriaxone for this Hib strain was $0.01 \mu \mathrm{g} / \mathrm{ml}$.

A final inoculum of $\sim 1 \times 10^{6}$ colonies/ml taken from a culture which contained bacteria in a log phase of growth was prepared. Animals were then intracisternally inoculated with $0.2 \mathrm{ml}$ of this bacterial suspension.

\section{Experimental meningitis model}

This study was approved by the Institutional Review Board for Animal Research of The University of Texas Southwestern Medical Center at Dallas.

The rabbit model of experimental meningitis, originally described by Dacey and Sande (24), was used in a modified form. New Zealand White male rabbits $(2-3 \mathrm{~kg})$ were anesthetized with intramuscular injections of ketamine $(40 \mathrm{mg} / \mathrm{kg})$ and acepromazine $(3 \mathrm{mg} / \mathrm{kg})$ and placed in a stereotactic frame. A spinal needle was introduced into the cisterna magna and $0.2 \mathrm{ml}$ of CSF withdrawn. Animals were then inoculated with same volume of either Hib LOS or live Hib organisms. Subsequent CSF samples (0.2-0.3 ml) were obtained at different times according to study design. Immediately after collection, the CSF aliquots were analyzed for cell count and the remaining CSF was centrifuged at $5,000 \mathrm{rpm}$ for $5 \mathrm{~min}$, and the supernatants stored at $-70^{\circ} \mathrm{C}$ until assayed for lactate, protein, and TNF $\alpha$ activity. In experiments involving use of live organisms, bacterial densities in CSF were determined by standard bacteriologic techniques. Blood samples were also obtained at different times through auricular arterial punctures and processed for leukocyte counts and bacterial density determinations.

\section{Antibiotic and antiinflammatory products}

An intravenous injection of $100 \mathrm{mg} / \mathrm{kg}$ of ceftriaxone (Hoffmann-LaRoche, Inc., Nutley, NJ) was used. CSF and serum concentrations of antibiotic were measured by a validated (25) HPLC at different times $(6,12$, and $24 \mathrm{~h}$ after administration) in rabbits receiving various antiinflammatory regimens. Dexamethasone sodium phosphate (Merck Sharp \& Dohme, West Point, PA) was given as a single $1 \mathrm{mg} / \mathrm{kg}$ intravenous injection.

IB4 myeloma producing an anti-CD18 MAb (isotype IgG2ak) was obtained from Dr. S. D. Wright (Rockefeller University, New York). IB4 MAb recognizes the common CD18 component of leukocyte integrins, and thus is capable of neutralizing all three adhesion-promoting glycoproteins of the CD18 family (26). It was propagated initially in vitro in Iscoves's modified Dulbecco's medium supplemented with $10 \% \mathrm{FBS}$, and then as ascites in pathogen-free female $\mathrm{CD}_{2} \mathrm{~F}_{1}$ mice $(\mathrm{Ta}-$ conic Farms, Inc., Germantown, NY). A control murine myeloma that synthesizes OKM-1 (isotype IgG2bk) was purchased from ATCC and grown in vitro as described above. OKM-1 MAb recognizes the antiCD1 1 b component of the CR 3 receptor, but does not inhibit adhesion of leukocytes to endothelial cells. OKM-1 ascites was generated in pathogen-free retired breeder female Balb/c mice (Jackson Laboratory, Bar Harbor, ME). These MAbs were isolated from ascites fluid by chromatography on protein A-Sepharose (Pharmacia Fine Chemicals, Piscataway, NJ), and the purity was judged to be $>98 \%$ by SDS-PAGE. The MAb concentration of purified preparations was determined by $\mathrm{UV}_{280}$ absorbance. The endotoxin content of various MAb preparations was $24-27 \mathrm{pg} / \mathrm{mg}$ IgG as measured by quantitative limulus amebocyte lysate assay (Whittaker M. A. Bioproducts, Walkersville, MD).
ELISA assays were conducted to measure the plasma concentration of IB4 or OKM-1 MAbs. Immulon-2 (Dynatech Laboratories, Inc., Alexandria, VA) 96-well plates were coated with affinity-purified rabbit anti-mouse IgG2a (Zymed Labs Inc., San Francisco, CA) for detection of IB4, or affinity-purified rabbit anti-mouse IgG2b (Zymed Labs) for detection of OKM-1. These trapping antibodies were dissolved at 5 $\mu \mathrm{g} / \mathrm{ml}$ in $0.1 \mathrm{M} \mathrm{NaHCO} 3$ for $1 \mathrm{~h}$ at $25^{\circ} \mathrm{C}$. After this and all subsequent steps, washing was performed with PBS using a ProPette automated plate washer (Cetus Corp., Emeryville, CA). Samples of rabbit plasma containing unknown amounts of IB4 or OKM-1 were diluted in PBS containing $0.05 \%$ Tween- 20 and $0.1 \%$ BSA and added to the wells; $100-\mu \mathrm{l}$ aliquots were incubated for $1 \mathrm{~h}$ at $37^{\circ} \mathrm{C}$ in triplicate. Standard calibration curves were constructed using purified IB4 or OKM-1 at concentrations ranging from 10 to $400 \mathrm{ng} / \mathrm{ml}$. After washing, bound IB4 or OKM-1 were detected with a 1:500 dilution (in PBS containing $1 \%$ BSA) of alkaline phosphatase-conjugated affinity-purified rabbit anti-mouse IgG2a (Zymed Labs) for IB4 and anti-mouse IgG2b for detection of OKM-1. After incubation for $1 \mathrm{~h}$ at $37^{\circ} \mathrm{C}$ and further washing, the quantities of bound conjugate were detected by incubating all wells with a $1 \mathrm{mg} / \mathrm{ml}$ solution of $p$-nitrophenyl phosphate in 0.1 M 2,2 amino-methyl-propanediol buffer (pH 10.3, Zymed Labs) for 30 min at $25^{\circ} \mathrm{C}$. The absorbance of each well was determined at $405 \mathrm{~nm}$ with a UV Max ELISA plate reader (Molecular Devices, Inc., Menlo Park, CA), and the plasma concentrations of IB4 or OKM-1 calculated using the accompanying software (Molecular Devices, Inc.).

\section{Study design}

Three different sets of experiments were conducted: $(a)$ Hib LOS-induced meningitis. $(b)$ Hib-live organism-induced meningitis without antibiotic treatment. (c) Hib-live organism-induced meningitis with antibiotic treatment.

Experiment 1. 36 rabbits received $20 \mathrm{ng}$ of endotoxin intracisternally and were allocated to receive intravenously OKM-1 MAbs ( $n$ $=6)$, IB4 MAbs $(n=11)$, DXM $(n=6)$, IB4 MAbs plus DXM $(n=6)$, or nothing $(n=7)$. All substances were given in a dose of $1 \mathrm{mg} / \mathrm{kg}$ administered $15 \mathrm{~min}$ before endotoxin challenge. Aliquots of CSF were then obtained at $2,6,12$, and $24 \mathrm{~h}$ after intracisternal LOS inoculation and analyzed for leukocyte counts and for protein, lactate, and TNF $\alpha$ concentrations.

Experiment 2. To assess contribution of leukocytes to development of brain edema and to evaluate their ability to halt CSF bacterial proliferation without antibiotic therapy, 33 rabbits were allocated to three different groups after being intracisternally inoculated with $2 \times 10^{5}$ live Hib organisms. Some animals received a dose of $1 \mathrm{mg} / \mathrm{kg}$ of IB4 Mabs with $(n=11)$ or without $(n=11) 1 \mathrm{mg} / \mathrm{kg}$ of DXM, and 11 rabbits were not treated (control group). Aliquots of CSF were obtained at 6, 12, and some at $24 \mathrm{~h}$ after intracisternal bacterial challenge and analyzed for leukocyte counts, bacterial densities, and for protein, lactate, and TNF $\alpha$ concentrations. Six animals from each group were sacrificed at $18 \mathrm{~h}$ for determination of brain water content. Additionally, aliquots of $1 \mathrm{ml}$ of blood were withdrawn at concordant times with CSF removal and analyzed for leukocyte and bacterial colony counts, and concentrations of IB4 or OKM-1 antibodies.

Experiment 3. The last set of experiments was designed to assess the effect of intravenous antibiotic therapy $(100 \mathrm{mg} / \mathrm{kg}$ ceftriaxone) on meningeal inflammation, brain edema, and bacterial counts in CSF and blood with and without concomitant antiinflammatory therapies. An inoculum of $2 \times 10^{5}$ live Hib organisms was intracisternally inoculated to 60 animals at zero hours. There were five therapeutic groups, consisting of six rabbits in group 1 and 14 rabbits in each of the other four groups, and except for group number 1 (untreated controls), all animals received at $6 \mathrm{~h}$ after intracisternal bacterial inoculation an intravenous dose of ceftriaxone. Animals in group 2 received antibiotic but no adjuvant therapy. Rabbits in groups 3,4 , and 5 were assigned to DXM (1 mg/kg), IB4 MAbs (1 mg/kg), and DXM plus IB4 MAbs (same doses), respectively. In all cases adjuvant therapy was given 15 min before administration of ceftriaxone. Aliquots of CSF were obtained at $6 \mathrm{~h}$ (just before antibiotic treatment), 12, 18, and some at $24 \mathrm{~h}$ 
after bacterial challenge and analyzed for leukocyte counts, bacterial densities, and for protein, lactate, and TNF $\alpha$ concentrations. Ceftriaxone concentrations in CSF and serum were also determined in some of these animals. Eight rabbits each from groups 2-5 were sacrificed at 18 $\mathrm{h}$ (12 h after antibiotic therapy) for determination of brain water content. In addition, aliquots of $1 \mathrm{ml}$ of blood were withdrawn at concordant times with CSF removal and analyzed for leukocyte and bacterial colony counts. To assess the effects of higher doses of IB4 MAbs on meningeal inflammation and brain edema six animals received intravenously a dose of $2.5 \mathrm{mg} / \mathrm{kg}$ and three rabbits were treated with a dose of $5 \mathrm{mg} / \mathrm{kg}$.

\section{Measurement of brain water content}

$18 \mathrm{~h}$ after induction of meningitis the animals were sacrificed by an overdose (150 mg per rabbit) of pentobarbital given intravenously. Immediately after death, a craniotomy was performed, and the brain, without the cerebellum and medulla, was removed and weighed in aluminum boats. The brain was then dried to stable weight (5-7 d) in a vacuum oven (Precision Scientific Group, Chicago, IL) at a temperature of $105^{\circ} \mathrm{C}$ and a vacuum of -50 to $-60 \mathrm{kPa}$. For comparison, 15 uninfected rabbits were killed, and their brain water contents were measured. Additionally, 12 brains of uninfected animals that received either DXM $(1 \mathrm{mg} / \mathrm{kg})$ or IB4 MAbs $(1 \mathrm{mg} / \mathrm{kg})$ were weighed $12 \mathrm{~h}$ after antiinflammatory treatment. The brain water content, expressed as grams of water per $100 \mathrm{~g}$ of dry weight, was determined and used as an estimate of brain edema. The brain water content was calculated by using the following formula: brain water content $=($ wet weight - dry weight)/dry weight $\times 100$.

\section{Cytolytic assay for $T N F \alpha$}

TNF $\alpha$ activity was determined by a previously described cytotoxic assay (27). Briefly, CSF samples were added to 96-2311 ELISA plates containing $7 \times 10^{4} \mathrm{~L} 929$ cells/well and the degree of cytotoxicity was quantified spectrophotometrically $(490 \mathrm{~nm})$. Equivalent concentrations of TNF $\alpha$ were determined for experimental samples by interpolation of known concentrations of rabbit TNF $\alpha$ run simultaneously ( $1 \mathrm{pg}$ to $1 \mu \mathrm{g} / \mathrm{ml})$. The minimal amount of detectable TNF $\alpha$ activity using these conditions was $10 \mathrm{pg} / \mathrm{ml}$. The specificity of the results was confirmed by adding an anti-rabbit TNF $\alpha$ monoclonal antibody to positive samples and documentation of complete neutralization of cytotoxicity. TNF $\alpha$ activity in CSF from healthy, uninfected rabbits was below the limits of detectability (3).

\section{Measurement of inflammatory indices}

Leukocyte counts in CSF and blood were determined by the use of a Neubauer hematocytometer (American Optical, Buffalo, NY). Samples were also stained with Wright solution to evaluate leukocyte histology.

Lactate concentrations in CSF were determined by a kinetic enzymatic method that used the reaction of lactate with nicotinamide-adenine dinucleotide (NAD) in the presence of lactate dehydrogenase to produce NAD, reduced NADH, and pyruvate. The production of NADH was quantified spectrophotometrically $(340 \mathrm{~nm})$. The precision of the method was tested by running a known standard of $40 \mathrm{mg} / \mathrm{dl}$ 10 times in $1 \mathrm{~d}$. The coefficient of variation was around $2 \%$.

Protein concentrations in CSF were measured by a modified biuret assay on the Ektachem 700 (Eastman Kodak Co., Rochester, NY). In this method, protein in a moderately alkaline solution chelates $\mathrm{Cu}^{++}$ ions from an azo dye, resulting in a spectral shift. The decrease in absorbance of the copper-azo dye complex is related to the concentration of protein in the sample. This method detects albumin and globulins.

\section{Statistical analysis}

Multiway repeated measures analysis of variance (ANOVA) was used to assess the effect of independent treatments with time for the following variables: leukocytes, protein, and lactate concentrations, log CFU/ $\mathrm{ml}$ of Hib organisms in CSF, and CSF concentrations of ceftriaxone.
Values of each variable obtained at four or five different time points were included in the analysis. Peak TNF $\alpha$, protein, and lactate concentrations in CSF, peak CSF, and blood leukocyte counts, and brain water content determinations among different treatment groups were analyzed by the Kruskal Wallis multiple comparison test. To compare percent of rabbits with positive initial blood cultures the two-tailed Fisher's exact test was applied.

All data are expressed as mean $\pm 1 \mathrm{SD}$, unless otherwise indicated. $P$ values $<0.05$ were considered significant.

\section{Results}

Experiment 1 (LOS-induced meningitis). After LOS inoculation, peak TNF $\alpha$ concentrations were detected at $2 \mathrm{~h}$, peak lactate and protein concentrations at $6 \mathrm{~h}$, and peak pleocytosis at $12 \mathrm{~h}$. Similar meningeal inflammatory changes were observed throughout the entire $24-\mathrm{h}$ period in animals that received control monoclonal antibodies (OKM-1 MAbs) and those in the untreated group (Table I). CSF pleocytosis was detected as early as $2 \mathrm{~h}$ after LOS intracisternal inoculation in $100 \%$ of these animals.

After $1 \mathrm{mg} / \mathrm{kg}$ doses, plasma concentrations of IB4 and OKM-1 MAbs varied between 9.9 and $20.8 \mathrm{~g} / \mathrm{ml} 2 \mathrm{~h}$ after onset of treatment and between 5.7 and $8.8 \mathrm{~g} / \mathrm{ml}$ at $12 \mathrm{~h}$. Half-lives of both antibodies in plasma were 10.1 and $13.4 \mathrm{~h}$, respectively. These results indicate that the effects of IB4 reported herein are specifically due to the anti-CD18 properties of IB4 and not caused by the mere presence of murine MAbs in the rabbit circulation.

Administration of either dexamethasone (DXM) or IB4 Mabs before LOS challenge was associated with a significant reduction in the number of leukocytes present in CSF over time with no differences detected between values in these two groups. Presence of pleocytosis at $2 \mathrm{~h}$ was detected in five of 11 animals that received IB4 MAbs and in three of six DXMtreated rabbits. A highly significant attenuation of CSF pleocytosis was observed over time when IB4 and DXM were given together compared with results after each agent was given alone $(P<0.05$, ANOVA over time). With combined therapy no more than 200 leukocytes $/ \mathrm{mm}^{3}$ was seen at any time after LOS administration and only one animal had detectable pleocytosis at $2 \mathrm{~h}$.

Administration of either DXM or DXM + IB4 MAbs was associated with significant reduction in TNF $\alpha$ activity in CSF compared with that detected in the remaining three groups. Mean concentrations of this cytokine were similar in rabbits receiving OKM-1 MAbs, IB4 MAbs, or no therapy (Table I).

Lactate concentrations in CSF were also significantly reduced over time when DXM was given either alone or in combination with IB4 MAbs. Similar high mean lactate values were detected in the other three groups.

Administration of either IB4 MAbs, DXM, or the combination of both, was accompanied by a significant attenuation of mean CSF protein concentrations over time compared with those in the other two groups.

Experiment 2 (nonantibiotic treated $H$. influenzae-induced meningitis). Animals receiving combination therapy with IB4 MAbs plus DXM showed a highly significant over time reduction in CSF pleocytosis, protein, lactate, and TNF $\alpha$ concentrations compared with those values observed in the untreated control group. In addition, leukocyte, TNF $\alpha$, and lactate concentrations were also significantly lower when both agents were 
Table I. Mean Peak CSF Inflammatory Indices in Rabbits with LOS-induced Meningitis Treated with Various Antiinflammatory Agents

\begin{tabular}{|c|c|c|c|c|c|c|}
\hline \multirow[b]{3}{*}{ Indices } & \multicolumn{5}{|c|}{ Groups } & \multirow{3}{*}{$\begin{array}{c}\text { Significant } \\
\text { differences } \\
\text { among groups* }\end{array}$} \\
\hline & 1 & 2 & 3 & 4 & 5 & \\
\hline & $\begin{array}{l}\text { No treatment } \\
\quad(n=7)\end{array}$ & $\begin{array}{l}\text { OKM-1 MAb } \\
\quad(n=6)\end{array}$ & $\begin{array}{l}\text { IB4 MAb } \\
(n=11)\end{array}$ & $\begin{array}{c}\text { DXM } \\
(n=6)\end{array}$ & $\begin{array}{c}\mathrm{DXM}+1 \mathrm{~B} 4 \\
(n=6)\end{array}$ & \\
\hline Leukocytes $/ \mathrm{mm}^{3}$ & $13171 \pm 6536$ & $14017 \pm 8134$ & $2130 \pm 1645$ & $2783 \pm 1657$ & $90 \pm 58$ & $\begin{array}{l}5 \text { vs. } 3 \text { and } 4 \\
3 \text { and } 4 \text { vs. } 1 \text { and } 2\end{array}$ \\
\hline Lactate $(m g / d l)$ & $50.0 \pm 9.5$ & $53.1 \pm 10.3$ & $47.3 \pm 10.7$ & $33.1 \pm 3.4$ & $30.0 \pm 2.8$ & 4 and 5 vs. $1-3$ \\
\hline Protein $(m g / d l)$ & $92.4 \pm 11.5$ & $90.8 \pm 10.2$ & $58.7 \pm 7.4$ & $52.5 \pm 14.3$ & $40.7 \pm 14.9$ & $3-5$ vs. 1 and 2 \\
\hline TNF $(n g / m l)$ & $24.7 \pm 10.3$ & $20.0 \pm 11.8$ & $19.5 \pm 11.1$ & $2.6 \pm 1.7$ & $2.5 \pm 1.5$ & 4 and 5 vs. $1-3$ \\
\hline
\end{tabular}

OKM-1 MAb, nonspecific monoclonal antibody, IB4 MAb, anti-CD18 receptor monoclonal antibody. Peak pleocytosis was observed between 6 and $12 \mathrm{~h}$, peak protein and lactate concentrations at $6 \mathrm{~h}$, and peak TNF activity at $2 \mathrm{~h}$ after LOS intracisternal inoculation. Antiinflammatory agents were given $15 \mathrm{~min}$ before LOS. ${ }^{*} P$ value of $<0.05$ was considered significant (Kruskal-Wallis multiple comparison test).

given together compared with results in animals that received IB4 MAbs alone. The peak values of all these inflammatory indices were detected at $12 \mathrm{~h}$ after intracisternal inoculation of live $H$. influenzae organisms (Table II).

A higher CSF multiplication of bacteria was seen in those animals that received IB4 MAbs. This finding, however, was only significant for the combination therapy compared with those values observed in rabbits assigned to the control untreated group (Table II). Although comparable bacterial densities were detected in blood cultures of all three groups taken at similar times $(6 \mathrm{~h}, 12 \mathrm{~h})$ as CSF, bacteremia $(6 \mathrm{~h})$ was present early in 11 of $11(100 \%)$ untreated animals compared with in seven of $11(67 \%)$ and in six of $11(56 \%)$ rabbits receiving IB4 MAbs and IB4 + DXM, respectively $(P=0.015$, Fisher's test comparing IB4-treated with untreated rabbits).

The mean brain water content values were similar in both treated groups of animals and substantially lower than those measured in untreated control rabbits (Table II). The difference in values was significant for only those animals that received combined therapy. Normal brain water content mea- sured in 14 uninfected animals was $400.1 \pm 11.8 \mathrm{~g}$ of water/100 $\mathrm{g}$ of dry weight. Likewise, similar brain water contents were measured in eight uninfected rabbits $12 \mathrm{~h}$ after treatment with DXM and six uninfected animals treated with IB4 MAbs (data not shown).

There was a significant increase in blood leukocyte counts when animals were treated with IB4 MAbs (normal values in rabbits are from 6,000 to $10,000 \mathrm{WBCs} / \mathrm{mm}^{3}$ ), either with or without DXM, compared with values in the control group. In the latter group leukopenia was detected at $6 \mathrm{~h}$ (mean $\pm 1 \mathrm{SD}$ : $3,817 \pm 1,330)$ and at $12 \mathrm{~h}(3,383 \pm 1,485)$ after intracisternal bacterial challenge, whereas values at $6 \mathrm{~h}$ of $13,483 \pm 5,814$ and $11,950 \pm 5,476$, and at $12 \mathrm{~h}$ of $7,083 \pm 3,040$ and 7,383 $\pm 2,328$, were found in animals receiving IB4 MAbs and IB4 MAbs + DXM, respectively $(P<0.05$ ANOVA over time).

Experiment 3 (antibiotic-treated $H$. influenzae induced meningitis). A total of 62 animals were assigned to five different groups, six in group 1 (untreated rabbits), and 14 in each of the following groups: group 2 (ceftriaxone alone), group 3 (ceftriaxone + DXM), group 4 (ceftriaxone + IB4 MAbs), and

Table II. Mean Peak CSF Inflammatory Indices and Bacterial Densities, and Brain Water Content, in Rabbits with H. influenzae-induced Meningitis Treated with Antiinflammatory Agents and without Antibiotic Therapy

\begin{tabular}{|c|c|c|c|c|}
\hline Indices & $\frac{1}{\begin{array}{c}\text { No treatment } \\
(n=11)\end{array}}$ & $\begin{array}{c}\begin{array}{c}\text { Groups } \\
2\end{array} \\
\begin{array}{c}\text { IB4 MAb } \\
(n=11)\end{array}\end{array}$ & 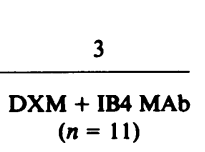 & $\begin{array}{c}\text { Significant } \\
\text { differences } \\
\text { among groups* }\end{array}$ \\
\hline Leukocytes $/ \mathrm{mm}^{3}$ & $7655 \pm 3877$ & $416 \pm 554$ & $13 \pm 10$ & 3 vs. 2 vs. 1 \\
\hline Lactate $(m g / d l)$ & $62.0 \pm 12.7$ & $59.3 \pm 14.1$ & $40.7 \pm 8.3$ & 3 vs. 2 and 1 \\
\hline Protein $(m g / d l)$ & $83.4 \pm 17.4$ & $44.3 \pm 8.2$ & $38.7 \pm 8.2$ & 2 and 3 vs. 1 \\
\hline $\mathrm{TNF}(n g / m l)$ & $4.9 \pm 2.7$ & $4.5 \pm 2.5$ & $1.0 \pm 0.6$ & 3 vs. 2 and 1 \\
\hline \multicolumn{5}{|l|}{ Bacterial density } \\
\hline at $6 \mathrm{~h}\left(\log _{10} C F U / m l\right)$ & $6.3 \pm 0.4$ & $6.6 \pm 0.3$ & $6.6 \pm 0.3$ & \multirow[t]{2}{*}{1 vs. 3} \\
\hline $\begin{array}{l}\text { Bacterial density } \\
\text { at } 12 \mathrm{~h}\left(\log _{10} C F U / m l\right)\end{array}$ & $6.6 \pm 0.5$ & $7.0 \pm 0.3$ & $7.4 \pm 0.4$ & \\
\hline \multicolumn{5}{|l|}{ Brain water content $t^{\ddagger}$} \\
\hline$\left(g \mathrm{H}_{2} \mathrm{O} / 100 \mathrm{~g} d r y w t\right)$ & $414.3 \pm 7.6$ & $404.0 \pm 9.4$ & $400.7 \pm 6.7$ & 3 vs. 1 \\
\hline
\end{tabular}

IB4 MAb, anti-CD18 receptor monoclonal antibody. All peak values were observed $12 \mathrm{~h}$ after intracisternal inoculation of $H$. influenzae organisms. Antiinflammatory agents were given $15 \mathrm{~min}$ before induction of meningitis. ${ }^{*} P$ value of $<0.05$ was considered significant. The Kruskal-Wallis multiple comparison test was used for all indices except for bacterial density in which a repeated measures ANOVA was employed. ${ }^{\ddagger}$ Brain water content was determined $18 \mathrm{~h}$ after induction of meningitis (six rabbits in each group). Normal brain water content measured in 14 uninfected animals was $400.1 \pm 11.8$. 
group 5 (ceftriaxone + IB4 + DXM). Similar CSF leukocyte, protein and lactate concentrations were detected in all groups before initiation of antibiotic therapy (Figs. 1-3). A highly significant antiinflammatory effect over time was observed when the combination of IB4 MAbs and DXM was given compared with results in all other treatment groups with the exception that DXM given alone was associated with similar reductions in lactate and TNF $\alpha$ concentrations. Treatment with IB4 MAbs alone did not result in reduction of TNF $\alpha$ and lactate concentrations; however, leukocyte and protein concentrations were similar to those seen after treatment with DXM alone (Figs. 1-3). The peak values of these inflammatory indices were detected at $6 \mathrm{~h}$ after ceftriaxone therapy for lactate and protein concentrations, at $12 \mathrm{~h}$ for leukocyte counts, and at $2 \mathrm{~h}$ for TNF $\alpha$ activity (Table III). The significant attenuating effect of combined therapy on meningeal inflammation is apparent.

Likewise, a substantial reduction in brain water content was obtained in the DXM plus IB4 therapy group compared with that in the other groups (Table III). When each antiinflammatory agent was given alone, however, a significantly lower brain water content was observed compared with that in animals given ceftriaxone therapy only.

Table IV shows the CSF bacterial densities at different times after onset of antibiotic treatment. Similar CSF bacterial clearance rates were observed in all antibiotic-treated animals regardless of the antiinflammatory modality employed. Three to four $\log$ reductions in CSF bacterial counts were detected by $12 \mathrm{~h}$ after onset of antibiotic treatment and by $18 \mathrm{~h}$ all treated animals had sterile CSF.

All animals before onset of ceftriaxone treatment were bacteremic and had similar bacterial counts in blood cultures. By 6 $h$ after initiation of antibiotic therapy all treated animals, regardless of antiinflammatory drug assignment, had sterile blood cultures.

Serum ceftriaxone concentrations were similar in all groups of animals. They ranged from 41.5 to $60.1 \mu \mathrm{g} / \mathrm{ml} 6 \mathrm{~h}$ after antibiotic administration and from 1.2 to $4.5 \mu \mathrm{g} / \mathrm{ml}$ at $24 \mathrm{~h}$. Lower concentrations were detected, however, in CSF of ani-

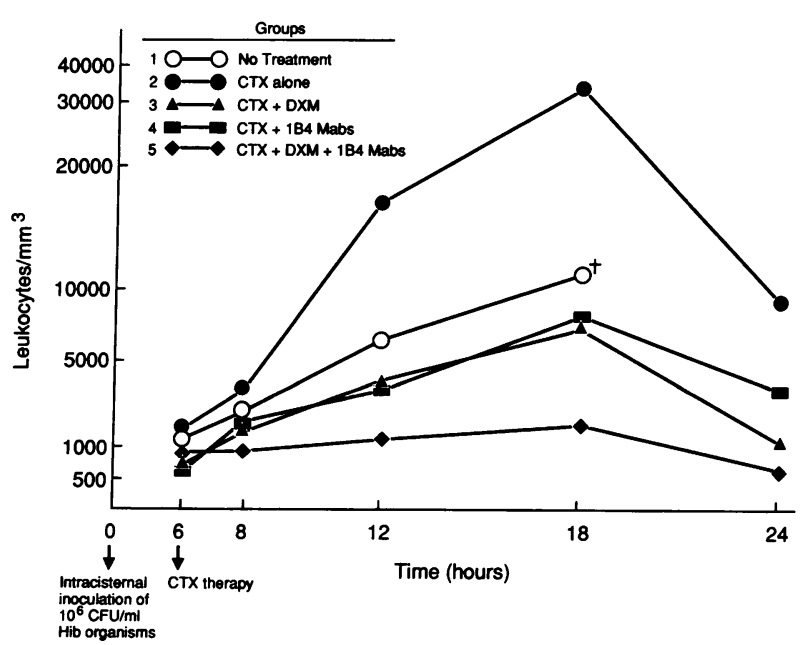

Figure 1. CSF pleocytosis over time in rabbits with $H$. influenzae-induced meningitis treated with various antiinflammatory agents before initiation of ceftriaxone (CTX) therapy. Significant differences (ANOVA $<0.05$ ) were detected between groups 5 vs. all others, 3 and 4 vs. 1 and 2 , and 1 vs. 2 . (+)Animals died at the time indicated.

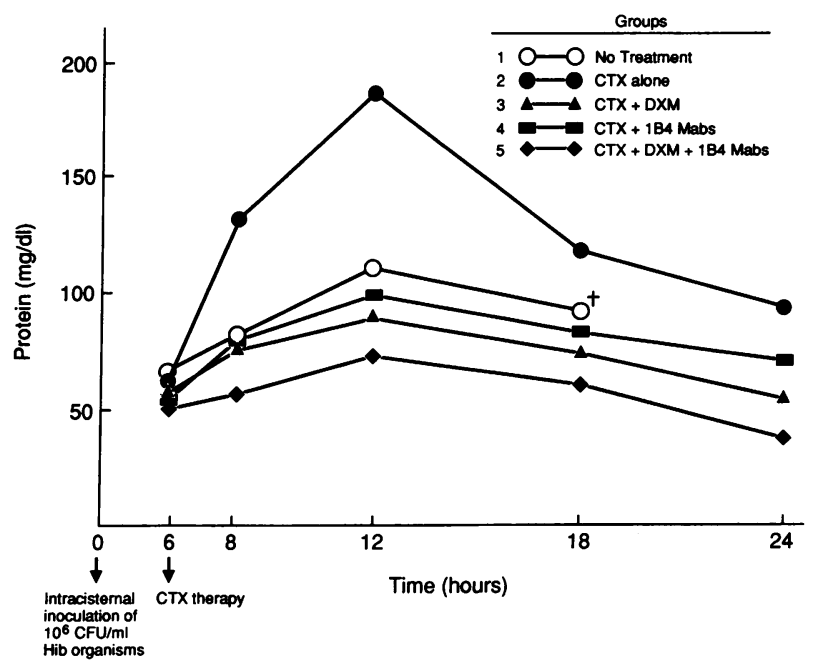

Figure 2. CSF protein concentrations over time in rabbits with $H$. influenzae-induced meningitis treated with various antiinflammatory agents before initiation of ceftriaxone (CTX) therapy. Significant differences (ANOVA < 0.05 ) were detected between groups 5 vs. all others, and 3 and 4 vs. 2. (+)Animals died at the time indicated.

mals that received antiinflammatory therapy. For rabbits given IB4, DXM, and IB4 + DXM, the mean \pm 1 SD CSF concentrations were of $8.4 \pm 1.5 \mu \mathrm{g} / \mathrm{ml}, 6.8 \pm 1.1 \mu \mathrm{g} / \mathrm{ml}$, and $5.4 \pm 0.9 \mu \mathrm{g} /$ $\mathrm{ml}$, respectively, at $6 \mathrm{~h}$ after antibiotic injection compared with $14.8 \pm 4.5 \mu \mathrm{g} / \mathrm{ml}$ measured in untreated animals $(P<0.05, A N-$ OVA). At $24 \mathrm{~h}, \mathrm{CSF}$ concentrations ranged from 0.6 to 1.0 $\mu \mathrm{g} / \mathrm{ml}$ in the treated group, whereas untreated rabbits had values ranging from 1.2 to $2.2 \mu \mathrm{g} / \mathrm{ml}$.

Determinations of the time course of IB4 plasma concentrations in the presence or absence of DXM after intracisternal inoculation of live $H$. influenzae organisms are presented in Table V. The concentrations and half-life values of circulating

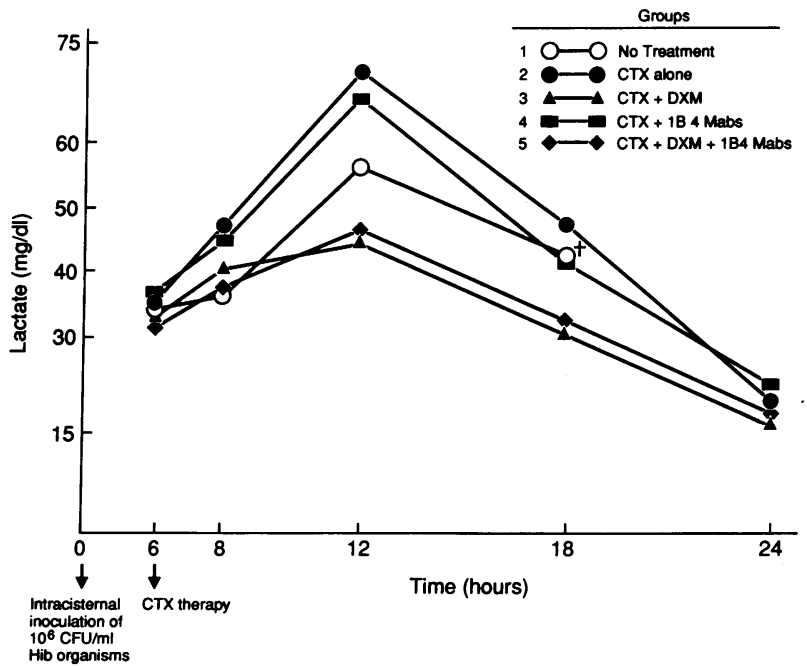

Figure 3. CSF lactate concentrations over time in rabbits with $H$. influenzae-induced meningitis treated with various antiinflammatory agents before initiation of ceftriaxone (CTX) therapy. Significant differences (ANOVA < 0.05 ) were detected between groups 3 and 5 vs. all others. (+)Animals died at the time indicated. 
Table III. Mean Peak CSF Inflammatory Indices and Brain Water Content in H. influenzae-infected Rabbits Treated with Various Antiinflammatory Agents before Antibiotic Treatment

\begin{tabular}{|c|c|c|c|c|c|c|}
\hline \multirow[b]{3}{*}{ Indices } & \multicolumn{5}{|c|}{ Groups } & \multirow[b]{3}{*}{$\begin{array}{l}\text { Significant } \\
\text { differences* }\end{array}$} \\
\hline & 1 & 2 & 3 & 4 & 5 & \\
\hline & $\begin{array}{l}\text { No treatment } \\
\quad(n=6)\end{array}$ & $\begin{array}{c}\text { CTX alone } \\
(n=14)\end{array}$ & $\begin{array}{c}\text { CTX + DXM } \\
(n=14)\end{array}$ & $\begin{array}{c}\text { CTX + IB4 MAb } \\
(n=14)\end{array}$ & $\begin{array}{c}\text { CTX + DXM } \\
+ \text { IB4 MAb } \\
(n=14)\end{array}$ & \\
\hline Leukocytes $/ \mathrm{mm}^{3}$ & $11938 \pm 5991$ & $31286 \pm 9872$ & $7386 \pm 2502$ & $7529 \pm 2738$ & $1754 \pm 661$ & $\begin{array}{l}5 \text { vs. } 1-4 \\
3 \text { and } 4 \text { vs. } 2 \\
1 \text { vs. } 2\end{array}$ \\
\hline Lactate $(m g / d l)$ & $58.9 \pm 15.2$ & $70.1 \pm 14.7$ & $41.5 \pm 7.5$ & $66.0 \pm 19.2$ & $43.1 \pm 6.0$ & 3 and 5 vs. $1,2,4$ \\
\hline Protein $(m g / d l)$ & $109.5 \pm 31.9$ & $181.9 \pm 40.9$ & $87.7 \pm 23.8$ & $98.1 \pm 33.8$ & $70.1 \pm 24.3$ & $3-5$ vs. 2 \\
\hline TNF $(n g / m l)$ & $3.7 \pm 3.1$ & $22.2 \pm 8.1$ & $7.0 \pm 3.5$ & $17.9 \pm 4.8$ & $8.1 \pm 3.0$ & $1,3,5$ vs. 2 and 4 \\
\hline \multicolumn{7}{|l|}{ Brain water content ${ }^{\ddagger}$} \\
\hline
\end{tabular}

CTX, ceftriaxone; IB4 MAb, anti-CD18 receptor antibody. Peak TNF activity was detected at $2 \mathrm{~h}$, peak lactate and protein concentrations at $6 \mathrm{~h}$ and peak pleocytosis at $12 \mathrm{~h}$ after antibiotic administration. Ceftriaxone was given $6 \mathrm{~h}$ after induction of meningitis. Antiinflammatory agents were given $15 \mathrm{~min}$ before ceftriaxone. ${ }^{*} P$ value of $<0.05$ was considered significant (Kruskal-Wallis multiple comparison test). ${ }^{\ddagger}$ Brain water content was determined $12 \mathrm{~h}$ after ceftriaxone administration (six animals in group 1 and eight in each of groups 2-5). Normal brain water content measured in 14 uninfected animals was $400.1 \pm 11.8$.

IB4 MAbs are essentially equivalent whether or not DXM was administered throughout the observation period. All IB4 MAbs concentrations were in excess of the amounts needed to saturate leukocyte integrins on stimulated human PMNs (1 $\mu \mathrm{g} / \mathrm{ml}$, Dr. S. D. Wright, personal communication). No IB4 MAbs were detected in CSF at 6 or $12 \mathrm{~h}$ after their intravenous administration.

Peripheral leukocytosis (with $>90 \%$ polymorphonuclear cells) was observed in rabbits receiving IB4 MAbs therapy, either alone or combined with DXM, with maximal leukocyte counts of $18,667 \pm 5,193$, and $20,417 \pm 3,878$ white blood cells/ $\mathrm{mm}^{3}$, respectively, seen at $12 \mathrm{~h}$ after onset of antibiotic therapy compared with 7,500 $\pm 4,600$, and $9,800 \pm 3,300$ for animals that received CTX only, and CTX plus DXM, respectively ( $P$ $<0.05$, ANOVA over time). Of all treated animals followed for $24 \mathrm{~h}$ (six rabbits in each group), only one died. This rabbit received antibiotic therapy alone. The remaining animals were alive and looked well. As stipulated by our Institutional Review
Board for Animal Research the animals were sacrificed soon after completion of the experiments.

An additional two sets of experiments involving 14 rabbits were conducted to assess the effect of higher IB4 MAb doses on meningeal inflammation and brain edema. There were no statistically significant enhanced antiinflammatory effects when larger doses of IB4 MAbs were administered compared with results after the $1 \mathrm{mg} / \mathrm{kg}$ dose (Table VI) despite achievement of considerably higher IB4 serum concentrations $2 \mathrm{~h}$ after antibody administration; mean serum IB4 concentrations were $14.1 \pm 4.5,25.5 \pm 7.7$, and $66.8 \pm 13.6 \mu \mathrm{g} / \mathrm{ml}$ for the $1,2.5$, and 5 $\mathrm{mg} / \mathrm{kg}$ doses, respectively, whereas at $12 \mathrm{~h}$ values of $7.1 \pm 3.1$, $17.4 \pm 5.6$, and $35.4 \pm 7.9 \mu \mathrm{g} / \mathrm{ml}$, respectively, were detected.

\section{Discussion}

It is now recognized that further improvements in outcome from bacterial meningitis will most likely not come from the

Table IV. CSF Bacterial Densities at Different Times after Ceftriaxone Treatment (Zero Time) of Rabbits with H. influenzae Meningitis Receiving Different Antiinflammatory Agents

\begin{tabular}{|c|c|c|c|c|c|}
\hline \multirow[b]{3}{*}{ Time } & \multicolumn{5}{|c|}{ Groups* } \\
\hline & 1 & 2 & 3 & 4 & 5 \\
\hline & $\begin{array}{c}\text { No treatment } \\
(n=6)\end{array}$ & $\begin{array}{c}\text { CTX alone } \\
(n=14)\end{array}$ & $\begin{array}{c}\text { CTX + DXM } \\
(n=14)\end{array}$ & $\begin{array}{c}\mathrm{CTX}+\text { IB4 MAb } \\
(n=14)\end{array}$ & $\begin{array}{c}\text { CTX + DXM } \\
+ \text { IB4 MAb } \\
\quad(n=14)\end{array}$ \\
\hline \multicolumn{6}{|l|}{$h$} \\
\hline 0 & $6.4 \pm 0.7^{\ddagger}$ & $6.5 \pm 0.5$ & $6.6 \pm 0.8$ & $6.8 \pm 0.6$ & $6.5 \pm 0.7$ \\
\hline 6 & $6.8 \pm 1.0$ & $4.1 \pm 0.9$ & $4.2 \pm 0.8$ & $4.3 \pm 0.8$ & $4.8 \pm 1.0$ \\
\hline 12 & $7.7 \pm 0.5$ & $2.6 \pm 0.5$ & $3.1 \pm 0.3$ & $2.7 \pm 0.6$ & $3.3 \pm 0.5$ \\
\hline 18 & $-\$$ & 0 & 0 & 0 & 0 \\
\hline
\end{tabular}

CTX, ceftriaxone, IB4 MAb, anti-CD18 receptor monoclonal antibody. $H$. influenzae organisms were intracisternally inoculated $6 \mathrm{~h}$ before initiation of ceftriaxone (zero time). Antiinflammatory agents were administered $15 \mathrm{~min}$ before ceftriaxone was given. * Values in groups $2-5$ were statistically different from those in group 1 (repeated measures ANOVA over time). No differences were found among values in groups 2-5. ${ }^{\ddagger} \log _{10}$ of colony-forming units/ml. ${ }^{8}$ Five rabbits were dead by this time. 
Table V. Mean \pm SD Plasma Concentrations and Half-Life Values of IB4 MAb in Rabbits with H. influenzae-induced Meningitis in the Presence or Absence of Dexamethasone

\begin{tabular}{lcccccc}
\hline & \multicolumn{5}{c}{ Time $(h)$} & \\
\cline { 2 - 5 } Compounds* & 2 & 4 & 6 & 9 & $\mathrm{~T}^{1} \mathbf{2}^{*}$ \\
\hline & & $\mu g / m l$ & & \\
IB4 MAb & $9.1 \pm 2.1$ & $7.7 \pm 2.0$ & $5.7 \pm 0.9$ & $3.3 \pm 0.7$ & $2.6 \pm 0.7$ & 5.11 \\
IB4 + DXM & $7.7 \pm 2.0$ & $6.4 \pm 1.2$ & $5.1 \pm 1.1$ & $2.8 \pm 0.8$ & $2.1 \pm 0.5$ & 4.97 \\
\hline
\end{tabular}

* IB4 MAb (1 mg/kg) and DXM (1 mg/kg) were injected intravenously 15 min before bacterial challenge. ${ }^{\ddagger}$ Mean plasma half-lives of IB4 MAb (h).

advent of newer and more potent antimicrobial agents. Indeed, antibiotic therapy has been shown to transiently increase meningeal inflammation by provoking lysis of microorganisms resulting in abrupt release of active cell wall components into CSF that stimulate cytokine production $(28,29)$. Recent evidence indicates that antiinflammatory agents combined with antimicrobial therapy modulate many of the pathophysiological consequences of bacterial meningitis, thereby contributing to a better prognosis $(30,31)$.

Antiinflammatory drugs that already have been tested in experimental models of bacterial meningitis have included agents targeted to interfere either with one or more mediators of the inflammatory cascade or with recruitment of leukocytes across the blood brain barrier. Data generated in this study showed that a combination of both therapeutic approaches attenuated dramatically the principal indices of CNS inflammation that are measured in bacterial meningitis. These profound antiinflammatory effects of combination therapy with DXM and IB4 MAbs were not caused by different pharmacokinetics of IB4 MAbs resulting from treatment with DXM because plasma concentrations and half-lives of IB4 MAbs were similar whether or not DXM was concomitantly administered. In addition, increasing the dose of IB4 MAbs did not reduce meningeal inflammation compared with that after DXM plus $1 \mathrm{mg}$ / $\mathrm{kg}$ IB4 or $1 \mathrm{mg} / \mathrm{kg}$ IB4 alone, suggesting that the addition of dexamethasone to reduce cytokine overproduction contributed substantially to the profound modulation observed with combination therapy. It is unknown whether dexamethasone affects expression of CD18-independent adhesion receptors on brain endothelium and/or leukocyte surfaces which has been described for PMN adherence in the pulmonary circulation (32).

Influx of PMNs into CSF was significantly reduced when either dexamethasone or anti-CD18 monoclonal antibodies were given separately but it was further decreased following concomitant administration of both agents. To enter the subarachnoid space, PMNs must first adhere to the cerebral capillary endothelium (although it is unknown whether PMNs can go through the choroid plexus as well) through receptors located on both endothelial and white blood cell surfaces (33). Two main groups of surface receptors that are involved in this leukocyte-endothelium interaction have been identified (33, $34)$. The first group is the integrin receptor family that is comprised by several $\alpha / \beta$ heterodimeric transmembrane glycoproteins divided into subfamilies on the basis of structurally distinct $\beta$ chains. The $\beta 2$ subfamily is the most relevant because its receptors are exclusively expressed on leukocytes, and its three members CD11a/CD18 (LFA-1), CD11b/CD18 (CR3 or Mac1), CD11c/CD18 (p150,95) form the CD11/CD18 heterodimer complex. Each of these receptor molecules binds to their

Table VI. Mean CSF Inflammatory Indices and Brain Water Content in H. influenzae-infected Rabbits Treated with Various IB4 MAb Doses before Ceftriaxone Treatment

\begin{tabular}{|c|c|c|c|c|c|c|}
\hline \multirow[b]{3}{*}{ Indices } & \multirow[b]{3}{*}{ Time } & \multicolumn{4}{|c|}{ IB4 MAb groups } & \multirow[b]{3}{*}{$\begin{array}{c}\text { Signifcant } \\
\text { differences* }\end{array}$} \\
\hline & & 1 & 2 & 3 & 4 & \\
\hline & & $\begin{array}{l}1 \mathrm{mg} / \mathrm{kg} \\
(n=14)\end{array}$ & $\begin{array}{c}2.5 \mathrm{mg} / \mathrm{kg} \\
(n=6)\end{array}$ & $\begin{array}{l}5 \mathrm{mg} / \mathrm{kg} \\
(n=3)\end{array}$ & $\begin{array}{c}1 \mathrm{mg} / \mathrm{kg}+\mathrm{DXM} \\
(n=5)\end{array}$ & \\
\hline \multirow[t]{2}{*}{$\mathrm{WBC} / \mathrm{mm}^{3}$} & $6 \mathrm{~h}$ & $4212 \pm 1210$ & $3933 \pm 2495$ & $3433 \pm 2001$ & $900 \pm 787$ & \multirow[t]{2}{*}{4 vs. $1-3$} \\
\hline & $12 \mathrm{~h}$ & $7529 \pm 2738$ & $5083 \pm 2461$ & $5567 \pm 1401$ & $1580 \pm 965$ & \\
\hline Lactate & $6 \mathrm{~h}$ & $66.0 \pm 19.2$ & $69.1 \pm 10.4$ & $65.8 \pm 11.8$ & $48.2 \pm 11.5$ & \multirow[t]{2}{*}{4 vs. 1 and 2} \\
\hline$(m g / d l)$ & $12 \mathrm{~h}$ & $48.7 \pm 11.3$ & $57.7 \pm 21.8$ & $53.3 \pm 15.7$ & $39.3 \pm 20.4$ & \\
\hline Protein & $6 \mathrm{~h}$ & $98.1 \pm 33.8$ & $88.4 \pm 22.3$ & $87.6 \pm 16.8$ & $79.6 \pm 24.9$ & \multirow[t]{2}{*}{ NS } \\
\hline$(m g / d l)$ & $12 \mathrm{~h}$ & $88.5 \pm 21.2$ & $80.4 \pm 19.8$ & $76.5 \pm 20.1$ & $61.4 \pm 21.3$ & \\
\hline \multicolumn{7}{|l|}{ Brain water } \\
\hline content $^{\ddagger}$ & & $413.0 \pm 7.3$ & $409.1 \pm 13.3$ & $411.7 \pm 7.1$ & $404.8 \pm 6.8$ & NS \\
\hline
\end{tabular}

Ceftriaxone (CTX) was given $6 \mathrm{~h}$ after induction of meningitis. IB4 MAbs were given 15 min before CTX. CSF samples were obtained 6 and $12 \mathrm{~h}$ after CTX treatment. ${ }^{*} P$ values of $<0.05$ were considered significant (ANOVA over time for inflammatory indices and KruskalWallis multiple comparison test for brain water content determinations). ${ }^{\ddagger}$ Brain water content was determined $12 \mathrm{~h}$ after CTX treatment (eight animals in group 1, six in group 2, three in group 3, and five in group 4). Normal values measured in 14 uninfected animals were 400.1 $\pm 11.8 \mathrm{~g} \mathrm{H}_{2} \mathrm{O} / 100 \mathrm{~g}$ dry wt. 
complementary ligands (ICAM-1 or ICAM-2, iC $3 b$, and iC $3 b$, respectively) (33). The second group of cell surface receptors are called selectins in which the endothelial cell adhesion molecule-1 (ELAM-1) and the leukocyte adhesion molecule (LAM1) are thought to be also involved in leukocyte attachment to endothelium during acute inflammation (34). The fact that PMN migration across the blood-brain barrier was effectively blocked by administration of anti-CD18 MAbs indicates, as previously suggested by Tuomanen et al. (6), that the CD11/ CD18 receptor family is the most important mechanism by which leukocytes adhere to and traverse the cerebral capillary endothelium. Moreover, it has been already demonstrated that endothelial cells in the CNS express ICAM-1 (35), one of the CD11/CD18 receptor ligands. Whether the selectins are present on brain endothelium is presently unknown but in vitro studies suggest that even when selectins mediate adhesion, integrins are still required for the subsequent event of transendothelial migration (36). This may explain why congenital deficiency of the leukocyte integrins so completely inhibits neutrophil emigration from the blood (37).

There is strong evidence supporting the role of cytokines, such as TNF and IL-1, in the activation of these receptor complexes (33). This event could explain, at least in part, the effects of steroids in reducing transendothelial passage of leukocytes into CSF. In agreement with what has been demonstrated in both in vitro and in clinical trials $(1,31), \mathrm{TNF} \alpha$ concentrations in CSF after bacterial and endotoxin challenge were signifcantly attenuated when dexamethasone was part of the antiinflammatory regimen. Thus, the profound inhibition in migration of leukocytes across the blood-brain barrier observed in the present study after combining both agents was not an unexpected finding.

This complex cytokine-endothelium-leukocyte interaction is probably responsible for the initial disruption of the barrier by opening intercellular junctions and permitting the passage of serum proteins into the subarachnoidal space. In this regard, the administration of either dexamethasone or anti-CD18 MAbs, and especially of the combination of the two agents, resulted in a significant reduction of CSF protein concentrations compared with the high values detected in animals that received no anti-inflammatory therapy. As shown previously (3) the highest CSF concentrations of protein and leukocytes occurred in the infected rabbits that were treated with antibiotic alone, again emphasizing the abrupt and transient enhanced proinflammatory effect seen consistently in the few hours after initiation of antimicrobial therapy for bacterial meningitis.

The significant reduction of lactate concentrations in CSF in animals that received dexamethasone, either alone or combined with anti-CD18 MAbs, but not anti-CD18 MAbs alone was an unexpected finding. Elevation of lactate concentrations in CSF represents the shift to an anaerobic metabolism as a result of poor oxygen delivery and cerebral tissue perfusion. These pathophysiologic events occur when brain edema and intracranial hypertension compromise cerebral blood flow (38). At this time it is speculative to postulate that cytokine-induced cellular metabolic abnormalities rather than leukocytemediated events are mostly responsible for increased lactic acid concentrations.

Brain edema occurs in bacterial meningitis as a result of several factors acting in concert: alteration of the blood-brain barrier with subsequent vasogenic edema, cytotoxic activities of activated leukocytes, and interstitial fluid accumulation resulting from increased viscosity of the purulent, protein-rich CSF. The administration of each antiinflammatory therapeutic modality reduced substantially brain water content in these experiments, but the maximal effect was observed when dexamethasone and anti-CD18 MAbs were given concomitantly. Antibiotic treatment alone was associated with the greatest brain edema.

Although the ability of leukocytes to control CSF bacterial multiplication has been the subject of debate, recent investigations indicate that leukocyte phagocytic function in CSF is impaired $(1,2,6)$. Our results suggest that without antibiotic treatment leukocytes appear to have a modest bactericidal activity. Nevertheless, proliferation of bacteria continued to occur in the presence of large numbers of WBCs in CSF. When antibiotic treatment was administered, however, similar reductions were observed among all animals regardless of the antiinflammatory regimen and all CSF cultures were sterile by $18 \mathrm{~h}$.

Secondary bacteremia was detected at $6 \mathrm{~h}$ in all untreatedanimals, whereas this phenomenon was documented only in approximately two-thirds of the rabbits receiving either antiCD18 MAbs alone or combined with dexamethasone, suggesting as previously reported by Tuomanen et al. (6), that a delay in dissemination of bacteria to the vascular compartment occurred when disruption of the capillary endothelium of arachnoid villi is prevented or attenuated by administration of antiinflammatory agents. Likewise, CSF concentrations of ceftriaxone were consistently lower in animals treated with antiinflammatory therapy than in those that were untreated suggesting again decreased permeability of the blood-brain barrier. Bacterial clearance rates were, however, unaffected. A peripheral leukocytosis developed in rabbits receiving antiCD18 MAbs, a finding presumably due to stiffness of the WBC membrane and removal of leukocytes from small vessels. The interaction of these antibodies with leukocyte surfaces did not appear to compromise bacterial clearance from the vascular compartment because all groups of treated-animals had sterile blood cultures as early as $6 \mathrm{~h}$ after initiation of antibiotic treatment.

In summary, antiinflammatory therapy directed against the production of cytokines in CSF or specifically against recruitment of leukocytes into the subarachnoidal space is associated with a significant attenuation of meningeal inflammation and with a substantial reduction in brain water content in rabbits with bacterial meningitis. These modulating effects were more pronounced when both therapeutic modalities were combined. It is unknown, however, to what extent meningeal inflammation must be reduced to produce the maximal beneficial effect on outcome from bacterial meningitis. Bacterial clearance from either CSF or blood after initiation of ceftriaxone therapy was not affected by administration of dexamethasone, IB4 MAbs, or both. Investigation of the potential role that IB4 MAbs, with and without dexamethasone, may have in improving outcome from bacterial meningitis in humans when given in conjunction with antimicrobial drugs must await results of appropriate phase I studies of their pharmacokinetics and safety.

\section{Acknowledgments}

The excellent technical assistance of Lori Frank, Diana Kazazis, Soham Pandya, and Dr. Mónica Trujillo is greatly appreciated. We also 
thank Dr. S. D. Wright for helpful discussions and for the IB4 myeloma.

This work was supported by a grant from Merck Sharp \& Dohme Laboratories.

\section{References}

1. Saez-Llorens, X., O. Ramilo, M. M. Mustafa, J. Mertsola, and G. H. McCracken, Jr. 1990. The molecular pathophysiology of bacterial meningitis: current concepts and therapeutic implications. J. Pediatr. 116:671-689.

2. Tunkel, A. R., B. Wispelwey, and W. M. Scheld. 1990. Pathogenesis and pathophysiology of meningitis. Infect. Dis. Clin. N.A. 4:555-581.

3. Mustafa, M. M., O. Ramilo, E. J. Hansen, B. Beutler, and G. H. McCracken, Jr. 1989. Modulation of inflammation and cachectin (TNF) activity in relation to treatment of experimental Haemophilus influenzae meningitis. $J$. Infect. Dis. 160:1151-1153.

4. Tuomanen, E., B. Hengstler, R. Rich, M. A. Bray, O. Zak, and A. Tomasz. 1987. Non-steroidal anti-inflammatory agents in the therapy for experimental pneumococcal meningitis. J. Infect. Dis. 155:985-990.

5. Saez-Llorens, X., O. Ramilo, M. M. Mustafa, J. Mertsola, C. De Alba, K. Olsen, and G. H. McCracken, Jr. 1990. Pentoxifylline modulates meningeal inflammation in experimental bacterial meningitis. Antimicrob. Agents Chemother. 34:837-843.

6. Tuomanen, E. I., K. Saukkonen, S. Sande, C. Cioffe, and S. D. Wright. 1989. Reduction of inflammation, tissue damage, and mortality in bacterial meningitis in rabbits treated with monoclonal antibodies against adhesion-promoting receptors of leukocytes. J. Exp. Med. 170:659-669.

7. Beutler, B., and A. Cerami. 1988. Cachectin (tumor necrosis factor). A macrophage hormone governing cellular metabolism and inflammatory response. Endocr. Rev. 9:57-66.

8. Dinarello, C. A. 1988. Biology of interleukin-1. FASEB (Fed. Am. Soc. Exp. Biol.) J. 2:108-115.

9. Ramilo, O., X. Saez-Llorens, J. Mertsola, H. Jafari, K. D. Olsen, E. J. Hansen, M. Yoshinaga, S. Ohkawara, H. Nariuchi, and G. H. McCracken, Jr. 1990. Tumor necrosis factor/cachectin and interleukin-1B initiate meningeal inflammation. J. Exp. Med. 172:497-507.

10. Beutler, B., N. Krochin, I. W. Milsark, C. Luedke, and A. Cerami. 1986. Control of cachectin (tumor necrosis factor) synthesis: mechanisms of endotoxin resistance. Science (Wash. DC). 232:977-980.

11. Kern, J. A., R. J. Laneb, J. C. Reed, R. P. Daniele, and P. C. Nowell. 1988. Dexamethasone inhibition of interleukin-1 beta production by human monocytes. J. Clin. Invest. 81:237-244.

12. Fishman, R. A., K. Sligar, and R. B. Hake. 1977. Effects of leukocytes on brain metabolism in granulocytic brain edema. Ann. Neurol. 2:89-94.

13. Rothlein, R., M. Czajkowski, M. M. O'Neil, S. D. Martin, E. Mainolf and V. J. Merluzzi. 1988. Induction of intercellular adhesion molecule-1 on primary and continuous cell lines by pro-inflammatory cytokines. J. Immunol. 141:1665-1669.

14. Pober, J. S., L. A. LaPierre, A. H. Stolpen, T. A. Brock, T. A. Springer, W. Fiers, M. P. Bevilacqua, D. L. Mendrick, and M. A. Gimbrone. 1987. Activation of cultured human endothelial cells by recombinant lymphotoxin: comparison with tumor necrosis factor and interleukin-1 species. J. Immunol. 138:33193324.

15. Saukkonen, K., S. Sande, C. Cioffe, S. Wolpe, B. Sherry, A. Cerami, and E. Tuomanen. 1990. The role of cytokines in the generation of inflammation and tissue damage in experimental gram-positive meningitis. J. Exp. Med. 171:439448.

16. Arfors, K. E., C. Lundberg, L. Lindborn, K. Lundberg, P. G. Beatty, and J. M. Harlan. 1987. A monoclonal antibody to the membrane glycoprotein complex CD18 inhibits polymorphonuclear leukocyte accumulation and plasma leakage in vivo. Blood. 69:338-340.

17. Vedder, N. B., R. K. Winn, C. L. Rice, E. Y. Chi, K. E. Arfors, and J. M. Harlan. 1988. A monoclonal antibody to the adherence-promoting leukocyte glycoprotein, CD18, reduces organ injury and improves survival from hemorrhagic shock and resuscitation in rabbits. J. Clin. Invest. 81:939-944.

18. Westphal, O., and K. Jann. 1965. Bacterial lipopolysaccharides: extraction with phenol-water and further applications of the procedure. Methods Carbohydr. Chem. 5:83-90.

19. Johnson, K. G., and M. B. Perry. 1976. Improved techniques for the preparation of bacterial lipopolysaccharides. Can. J. Microbiol. 22:29-34.

20. Tsai, M., and C. T. Frasch. 1982. A sensitive silver stain for detecting lipopolysaccharides in polyacrylamide gels. Anal. Biochem. 119:115-119.

21. Kimura, A., and E. J. Hansen. 1986. Antigenic and phenotypic variations of Haemophilus influenzae type b lipopolysaccharide and their relationship to virulence. Infect. Immun. 51:69-79.

22. Syrogiannopoulos, G. A., E. J. Hansen, A. L. Erwin, R. S. Munford, J. Rutledge, J. S. Reisch, and G. H. McCracken, Jr. 1988. Haemophilus influenzae type b lipooligosaccharide induces meningeal inflammation. J. Infect. Dis. 157:237-244.

23. Gulig P. A., C. C. Patrick, L. Hermanstarfer, G. H. McCracken, and E. J. Hansen. 1987. Conservation of epitopes in the oligosaccharide portion of Haemophilus influenzae type b. Infect. Immun. 55:513-520.

24. Dacey, R. G., and M. A. Sande. 1974. Effects of probenecid on cerebrospinal fluid concentrations of penicillin and cephalosporin derivatives. Antimicrob. Agents Chemother. 6:437-441.

25. Jungbluth, G. L., and W. J. Jusko. 1989. Ion-paired reversed-phase highperformance liquid chromatography assay for determination of ceftriaxone in human plasma and urine. J. Pharm. Sci. 78:968-970.

26. Wright, S. D., P. E. Rao, W. C. Van Voorhis, L. S. Craigmyle, K. Iida M. A. Talle, E. F. Westberg, G. Goldstein, and S. C. Silverstein. 1983. Identification of the $\mathrm{C} 3 \mathrm{bi}$ receptor of human monocytes and macrophages by using monoclonal antibodies. Proc. Natl. Acad. Sci. USA. 80:5699-5703.

27. Flick, D. A., and G. E. Figgord. 1984. Comparison of in vivo cell cytotoxic assays for tumor necrosis factor. J. Immunol. Methods. 68:167-175.

28. Mertsola, J., O. Ramilo, M. M. Mustafa, X. Saez-Llorens, E. J. Hansen, and G. H. McCracken, Jr. 1989. Release of endotoxin after antibiotic treatment of Gram-negative bacterial meningitis. Pediatr. Infect. Dis. J. 8:904-906.

29. Tuomanen, E., H. Liu, B. Hengstler, O. Zak, and A. Tomasz. 1985. The induction of meningeal inflammation by components of the pneumococcal cell wall. J. Infect. Dis. 151:859-868.

30. McCracken, G. H., Jr., and M. H. Lebel. 1989. Dexamethasone therapy for bacterial meningitis in infants and children. Am. J. Dis. Child. 143:287-289.

31. Odio, C. M., I. Faingezicht, M. Paris, M. Nassar, A. Baltodano, J. Rogers, X. Sáez-Llorens, K. D. Olsen, and G. H. McCracken, Jr. 1991. The beneficial effects of early dexamethasone administration in infants and children with bacterial meningitis. N. Engl. J. Med. 324:1525-1531.

32. Doerschuk, C. M., R. K. Winn, H. O. Coxson, and J. M. Harlan. 1990. CD18-dependent and independent mechanisms of neutrophil emigration in the pulmonary and systemic microcirculation of rabbits. J. Immunol. 144:23272333.

33. Springer, T. A. 1990. Ahesion receptors of the immune system. Nature (Lond.). 346:425-433.

34. Arnaout, M. A. 1990. Structure and function of the leukocyte adhesion molecules CD11/CD18. Blood. 75:1037-1050.

35. Wilcox, C. E., A. M. V. Ward, A. Evans, D. Baker, R. Rothlein, and J. L. Turk. 1990. Endothelial cell expression of the intercellular adhesion molecule(ICAM-1) in the central nervous system of guinea pigs during acute and chronic relapsing experimental allergic encephalomyelitis. J. Neuroimmunol. 30:43-51.

36. Smith, C. W., S. D. Marlin, R. Rothlein, C. Toman, and D. C. Anderson. 1989. Cooperative interactions of LFA-1 and Mac-1 with intercellular adhesion molecule-1 in facilitating adherence and transendothelial migration of human neutrophils in vitro. J. Clin. Invest. 83:2008-2017.

37. Anderson, D. C., and T. A. Springer. 1987. Leukocyte adhesion deficiency: an inherited defect in the Mac-1, LFA-1, and p150,95 glycoproteins. Annu. Rev. Med. 38:175-194.

38. Tureen, J. H., R. J. Dworkin, S. L. Kennedy, M. Sachdeva, and M. A. Sande. 1990. Loss of cerebrovascular autoregulation in experimental meningitis in rabbits. J. Clin. Invest. 85:577-581. 